\title{
In Vitro Ultramorphological Assessment of Apoptosis Induced by Zerumbone on (HeLa)
}

\author{
Siddig Ibrahim Abdel Wahab, ${ }^{1}$ Ahmad Bustamam Abdul, ${ }^{1}$ Adel Sharaf Alzubairi, 1,2 \\ Manal Mohamed Elhassan, ${ }^{1}$ and Syam Mohan ${ }^{1}$ \\ ${ }^{1}$ UPM-MAKNA Cancer Research Laboratory, Institute of Bioscience, University Putra Malaysia, Serdang, 43400 Selangor, Malaysia \\ ${ }^{2}$ Department of Clinical Biochemistry, Faculty of Medicine and Health Sciences, University of Sana'a, Sana'a, Yemen
}

Correspondence should be addressed to Siddig Ibrahim Abdel Wahab, abustamam@putra.upm.edu.my

Received 7 August 2008; Revised 5 December 2008; Accepted 7 January 2009

Recommended by Yan Luo

Zerumbone (ZER), a potential anticancer compound, isolated from the fresh rhizomes of Zingiber zerumbet. In this investigation, the cytotoxic properties of ZER were evaluated, on cancer cells of human cervix (HeLa), breast and ovary, and normal cells of Chinese Hamster ovary, using MTT assay. Apoptogenic effects of ZER on HeLa were studied using fluorescence microscopy (AO/PI double staining), scanning and transmission electron microscopy (SEM and TEM), and colorimetric assay of the apoptosis promoter enzyme, caspase-3. The results of MTT assay showed that ZER has less effect on normal cells compared to cancer cells. The lowest $\mathrm{IC}_{50}$ of ZER was observed on HeLa cells. Cytological observations showed nuclear and chromatin condensation, cell shrinkage, multinucleation, abnormalities of mitochondrial cristae, membrane blebbing, holes, cytoplasmic extrusions and formation of apoptotic bodies as confirmed collectively by double staining of AO/PI, SEM and TEM. Statistical analysis (twotailed $t$-test) of differential counting of 200 cells under fluorescence microscope revealed significant difference in apoptotic cells populations between treated and untreated HeLa cells. In addition, ZER has increased the cellular level of caspase- 3 on the treated HeLa cells. It could be concluded that ZER was able to produce distinctive morphological features of cell death that corresponds to apoptosis.

Copyright ( 2009 Siddig Ibrahim Abdel Wahab et al. This is an open access article distributed under the Creative Commons Attribution License, which permits unrestricted use, distribution, and reproduction in any medium, provided the original work is properly cited.

\section{Introduction}

Natural products provide a great chemical structural diversity. In this respect, sesquiterpines have been demonstrated to stimulate cytotoxicity and apoptosis in several cancer cell lines at low micromolar concentrations with an acceptable clinical range of new anticancer drugs $[1,2]$. Sesquiterpene have been found abundantly in Zingiber zerumbet, a plant which is commonly found in Malaysia [3, 4]. Z. zerumbet has significant economic properties, as the rhizome can be used as both a spice and a traditional medicine. Zerumbone (ZER: Figure 1) is a monosesquiterpine, which is recognized as a main compound of this plant. ZER has shown antiproliferative effects on different cancer cell lines such as HT-29, CaCo-2, and HepG2 cancer cells, with extra investigations on apoptosis pathway and G2/M cell cycle arrest $[5,6]$. Moreover, cytotoxic effects of ZER have been reported to be selective toward cancer cells compared to normal cells $[4,7]$. Furthermore, the compound has shown potential in vivo chemopreventive properties on experimental skin cancer in mouse [8], colon cancer in rats [9], and cervical intraepithelial neoplasia in Balb/c mice [10]. In addition, ZER has shown anti-inflammatory (anticycloxygenase-2), suppression of free radical generation, anticholinesterase, iNOS expression, and TNF-a release $[9,11,12]$.

Cervical cancer remains a critical public health problem that is second only to breast cancer in overall disease burden for women throughout the world [13]. This cancer has been targeted by researchers to discover new anticancer drugs that can replace the current unsafe regimens for such disease [14]. Natural products are suitable alternatives that can be used instead of platinum-based drugs in control of cervical cancer, which show some harmful side effects [15]; however, a recent study has demonstrated that ZER is 


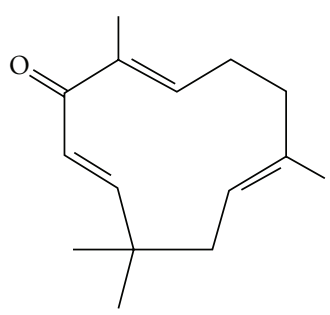

Figure 1: Chemical structure of zerumbone (molecular weight: 218.34).

significantly less harmful when tested on human peripheral blood lymphocytes compared to cisplatin [16]. On the other hand, ZER inhibited the proliferation of several cancer cell lines, while the growth of Chang normal liver cells, normalhuman dermal (2F0-C25), and colon (CCD-18 Co) fibroblasts wasless affected [4, 17]. With regards to the cytoselective toxicity and the versatile biological activities of this compound, the present study was suggested to explore its antiproliferative effects and the apoptogenic ontogeny on different cancer cells and human cervical cancer cell (HeLa), respectively.

\section{Materials and Methods}

2.1. Isolation and Characterization of ZER. ZER was isolated using the hydrodistillation (steam distillation) method. Briefly, fresh rhizomes of $Z$. zerumbet were initially cleaned and sliced and later placed in a glass flask containing distilled water and heated immediately using the heating mantel. The flask was immediately connected to special glassware (Dienstag) in order to collect vaporized steam containing the volatile oil. Then volatile oil was crystallized using circulating cool water. The crystals were collected and used. To obtain highly pure ZER, recrystalization was performed using hexane and the solution was left standing to evaporate. Thin layer chromatography was used to examine purification of ZER at each step. The crystals of ZER were kept for further chemical and pharmacological analyses.

2.2. ZER Structure Elucidation by NMR. Five milligrams of ZER crystals were dissolved in HPLC-grade methanol and the sample was subsequently sent for (nuclear magnetic resonance) NMR analysis at the laboratory of Natural Products, Institute of Bioscience, UPM. ${ }^{1}$ Hydrogen and ${ }^{13}$ Carbon NMR spectra were recorded in Varian Unity Inova spectrometer operated at $500 \mathrm{MHz}$, and the chemical shifts of the respective compound were reported in ppm.

2.3. Cell Culture and MTT Cytotoxicity Assay. Human cancer cell lines of cervix (HeLa), ovary (Coav-3) and breast (MCF-7), and Chinese Hamster ovary normal cells were obtained from American Type Culture Collection (ATCC, Va, USA). ATCC protocol recommended the use of RPMI 1640 (PAA, Cölbe, Germany) as a media for culturing cells. Disposable items ( $75 \mathrm{~mL}$ tissue culture flask, filter system, well plates) were purchased from (NUNC, Roskilde,
Denmark). Trypsin EDTA, feotal calf serum, amphotericin $\mathrm{B}$, and penicillin streptomycin were obtained from FlowLab (Australia). The microtetrazolium (MTT) powder was purchased from Amresco, Ohio, USA, and the dimethylsulphoxide (DMSO) was purchased from Sigma Aldrich, Germany.

Cells were trypsinized and counted using hemocytometer and plated in a microtiter plate of 96 wells. After an overnight incubation to allow cells attachment, medium was changed and $0.2 \mathrm{~mL}$ of new supplemented medium was added in each well. Cells were then treated in a dose- and time-dependent manners, with zerumbone, $0.1 \%$ ethanol (negative control), and cisplatin (positive control), and were incubated at $37^{\circ} \mathrm{C}$, $5 \% \mathrm{CO}_{2}$ for 72 hours. Each concentration of the compounds was assayed in triplicates. MTT assay reading was performed using ELISA plate reader (TECAN, SunriseTM, Männedorf, Switzerland).

2.4. Colorimetric Assays of Caspase-3. The colorimetric protease assay of caspase-3 provides a simple and convenient means for quantifying the enzyme activity that recognize the amino acid sequence, DEVD (a synthetic tetrapeptide, (Asp-Glue-Val-Asp), which is the upstream amino acid sequence of the caspase-3 cleavage site), coupled with pnitroanilide, which is released upon substrate cleavage. This assay was performed using commercial kit (ApoTarget kit, code: KHZ0022: BioSource International, Inc., Calif, USA). $2 \times 10^{6}$ cells were treated with $\mathrm{IC}_{50}$ of ZER and incubated for 72 hours while untreated cells acted as control. The cells were lysed by the addition of $50 \mu \mathrm{L}$ of chilled cell lysis buffer and incubated on ice for 10 minutes. The resulting cell lysate was centrifuged for 1 minute at $10000 \times \mathrm{g}$, and the supernatant was collected. Fifty microliters of $2 \mathrm{X}$ reaction buffer (containing $10 \mathrm{mM}$ DTT) were added to each sample. Then $5 \mu \mathrm{L}$ of DEVD-pNA (caspase- 3 substrate) was added and incubated in the dark at $37^{\circ} \mathrm{C}$ for 1 hour. At the end of the incubation period, the samples were read at $405 \mathrm{~nm}$ in a microplate reader (TECAN, SunriseTM, Männedorf, Switzerland). Data was presented as optical density (405 nm; mean $\pm \mathrm{SD})$.

2.5. Quantification of Apoptosis Using Propidium Iodide and Acridine Orange Double Staining. ZER-induced cell death in HeLa cancer cells was quantified using propidium iodide (PI) and acridine-orange (AO) double staining according to standard procedures and examine under fluorescence microscope (Lieca attached with Q-Floro Software) [18, 19]. Briefly, treatment was carried out in a $25 \mathrm{~mL}$ culture flask (Nunc). HeLa cells were plated at concentration of $1 \times$ $10^{6} \mathrm{cell} / \mathrm{mL}$, and treated with $\mathrm{ZER}$ at $\mathrm{IC}_{50}$ concentration. Flasks were incubated in atmosphere of $5 \% \mathrm{CO}_{2}$ at $37^{\circ} \mathrm{C}$ for 24,48 , and 72 hours. The cells were then spun down at $1000 \mathrm{rpm}$ for 10 minutes. Supernatant was discarded and the cells were washed twice using phosphate buffer saline (PBS) after centrifuging at $1000 \mathrm{rpm}$ for 10 minutes to remove the remaining media. Ten microliters of fluorescent dyes containing acridine orange $(\mathrm{AO}, 10 \mu \mathrm{g} / \mathrm{mL})$ and propidium iodide $(\mathrm{PI}, 10 \mu \mathrm{g} / \mathrm{mL})$ were added into the cellular pellet at equal volumes of each. Freshly stained cell suspension 
was dropped into a glass slide and covered by coverslip. Slides were observed under UV-fluorescence microscope within 30 minutes before the fluorescence color starts to fade. The percentages of viable, apoptotic, and necrotic cells were determined in more than 200 cells. Acridine orange (AO) and propidium iodide (PI) are intercalating nucleic acid specific fluorochromes which emit green and orange fluorescences, respectively, when they are bound to DNA. Of the two, only AO can cross the plasma membrane of viable and early apoptotic cells. Viewed by fluorescence microscopy, viable cells appear to have green nucleus with intact structure while apoptotic cells exhibit a bright-green nucleus showing condensation of chromatin as dense green areas. Late apoptotic cells and necrotic cells will stain with both $\mathrm{AO}$ and PI. Comparatively, PI produces the highest intensity emission. Hence, late apoptotic cells exhibited an orange nucleus showing condensation of chromatin whilst necrotic cells display an orange nucleus with intact structure. This assay provides a useful quantitative evaluation and was done three times $(n=3)$.

2.6. Transmission Unltrastructural Effects of ZER on HeLa Cells (TEM). HeLa cancer cells were cultured with the $\mathrm{IC}_{50}$ of ZER and cisplatin and incubated for 24, 48, and 72 hours at $37^{\circ} \mathrm{C}$. The cultured cells were harvested using trypsin and centrifuged for 10 minutes at $3500 \mathrm{rpm}$ and room temperature. The pellets were fixed in $4 \%(\mathrm{v} / \mathrm{v})$ glutaraldehyde in $0.1 \mathrm{M}$ coccadylate buffer $(\mathrm{pH} 7.4$ ) for 4 hours at $4^{\circ} \mathrm{C}$. The fixed cells were centrifuged, and the pellets were blocked in serum which was later fixed in glutaraldeyde overnight at $4^{\circ} \mathrm{C}$. The specimens were washed in three changes of sodium coccadylate buffer ( $\mathrm{pH}$ 7.4) for 10 minutes each, postfixed in $1 \%$ osmium tetraoxide at $4^{\circ} \mathrm{C}$. The specimens were then washed in three changes of sodium coccadylate buffer ( $\mathrm{pH} 7.4$ ) for 10 minutes each and dehydrated with a graded series of acetone $(35 \%, 50 \%, 75 \%$, $95 \%$, and $100 \%)$. The cells were then infiltrated with acetone and resin and embedded with $100 \%$ resin in beam capsule, and left to polymerize at $60^{\circ} \mathrm{C}$ for 48 hours. The area of interest in the embedded cells resin block was chosen using the toulidine blue staining and later examined using light microscope. The selected area was cut in ulltrathin sections using ultramicrotome. The sections were placed into a grid and stained with uranyl acetate for 10 minutes followed by $50 \%$ filtered acetone, and finally stained using lead which was then washed twice with distilled water. The stained samples were then viewed under transmission electron microscopy (Phillips, Eindhoven, The Netherlands).

2.7. Exterior Unltrastructural Effects of ZER on HeLa Cells $(S E M)$. The $\mathrm{IC}_{50}$ of ZER was used to induce death toward human cervical cancer cell lines (HeLa). HeLa cells were cultured for 24, 48, and 72 hours. The cancer cells were trypsinized and centrifuged for 10 minutes at $3000 \mathrm{rpm}$. The pellets were fixed in $4 \%(\mathrm{v} / \mathrm{v})$ glutaraldehyde in $0.1 \mathrm{M}$ coccadylate buffer ( $\mathrm{pH}$ 7.4) for 4 hours, $4^{\circ} \mathrm{C}$. The fixed cells were washed in three changes of sodium coccadylate buffer for 10 minutes each, postfixed in $1 \%$ osmium tetraoxide at $4^{\circ} \mathrm{C}$. The specimens were then washed in three changes of sodium coccadylate buffer ( $\mathrm{pH}$ 7.4) for 10 minutes each, dehydrated in ascending grades of acetone $35 \%, 50 \%, 75 \%$, $95 \%$, and $100 \%$ ), and brought to critical point of drying by the critical point drier (CPD 030, Bal-TEC, Switzerland) for thirty minutes. The cells were affixed to a metal SEM stub and sputter coated in gold by using SEM coating unit (E5100 Polaron, UK). The coated specimens were viewed using scanning electron microscopy (JOEL 64000, Japan) at accelerating voltage of $15-25 \mathrm{KV}$.

2.8. Statistical Analysis. Data was expressed as mean \pm SEM (mean $\pm \mathrm{SD})$. Normality and homogeneity of variance assumptions were checked. One way ANOVA followed by pairwise comparison analysis was used when needed. Independent $t$-test was used to analyze the data of the colorimetric assay of caspase. SPSS 16.0 was utilized to conduct statistical analysis. The value of 0.05 was considered as the cutoff point of type one error (alpha).

\section{Results}

3.1. ${ }^{13} C$ NMR and ${ }^{1} H$ NMR Analyses of ZER. NMR analyses were performed to verify the chemical structure of ZER before conducting further biological investigations. ${ }^{1} \mathrm{H}-$ NMR spectrum showed four singlets which resonate at $\delta$ $1.573, \delta 1.770, \delta 1.086$, and $\delta 1.238$, and they were due to the methyl group at carbon $\mathrm{C}-12, \mathrm{C}-13, \mathrm{C}-14$, and C15 (Figure 1). A broad duplet was found between $\delta 6.083$ and $\delta 6.106$ at C-6 position. Three multiplets between $\delta$ 2.243 and $\delta 2.544$ were attributed to the methylene groups at positions $\mathrm{C}-1, \mathrm{C}-4$, and $\mathrm{C}-5$, respectively. The ${ }^{13} \mathrm{C}-\mathrm{NMR}$ spectrum gave a total of fifteen carbons. The most downfield signal at $\delta 205.528$ was due to the carbonyl group at position $\mathrm{C}-8$. The signals of methyl group at positions C-12, C-13, C14 , and C-15 were observed at $\delta 14.228, \delta 10.724, \delta 23.360$, and $\delta 28.659$, respectively. These ${ }^{1} \mathrm{H}-\mathrm{NMR}$ and ${ }^{13} \mathrm{C}-\mathrm{NMR}$ analyses coincide to the chemical structure that resembles ZER (Figure 1).

3.2. Cytotoxic Effects of ZER on Normal and Cancer Cells. As depicted in Table 1, ZER was clearly found to exert antiproliferative effects toward HeLa, Coav-3, and MCF7. The $\mathrm{IC}_{50}$ value, which is the concentration required for $50 \%$ growth inhibition, is determined to be $20.30 \pm$ $1.1,24.30 \pm 0.9$, or $27.7 \pm 1.2 \mu \mathrm{M}$ against HeLa, Coav-3, or MCF-7, respectively. Comparatively, the anti-neoplastic drug, cisplatin, was used as a positive control in this study. Cisplatin revealed an inhibitory effect on HeLa, MCF-7, and Coav- 3 cancer cells with $\mathrm{IC}_{50}$ values of $5.45 \pm 0.44$, $4.9 \pm 1.8$, and $3.7 \pm 0.44 \mu \mathrm{M}$, respectively. ZER reveals a lower cytotoxicity (High $\mathrm{IC}_{50}$ ) toward normal cells Chinese hamster ovary (Table 1).

3.3. Colorimetric Assay of Caspase-3. Since HeLa were the most sensitive cells to ZER, an in vitro colorimetric assay of caspase- 3 was conducted to assess apoptosis between control and treated cells. As shown in Figure 2, ZER significantly 
TABLE 1: Effects of ZER and cisplatin on the viability of cancer and normal cells. Cells were cultured in RPMI 1640 media maintained at $37^{\circ} \mathrm{C}$ and $5 \% \mathrm{CO}_{2}$. The lowest $\mathrm{IC}_{50}$ of ZER was observed on HeLa cells.

\begin{tabular}{lcccc}
\hline Treatment & & & & \\
& HeLa & MCF-7 & Coav-3 & CHO \\
\hline ZER & $20.30 \pm 1.1 \mu \mathrm{M}$ & $27.7 \pm 1.2 \mu \mathrm{M}$ & $24.30 \pm 0.9 \mu \mathrm{M}$ & $35.80 \pm 5.1 \mu \mathrm{M}$ \\
Cisplatin & $5.45 \pm 0.44 \mu \mathrm{M}$ & $4.9 \pm 1.8 \mu \mathrm{M}$ & $3.7 \pm 0.44 \mu \mathrm{M}$ & $4.15 \pm 1.23 \mu \mathrm{M}$ \\
\hline
\end{tabular}

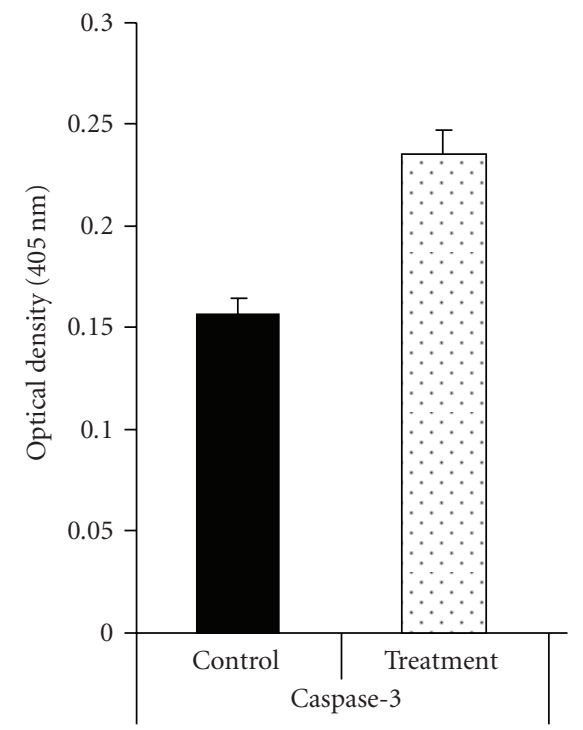

Figure 2: The colorimetric assay of caspase-3 in human cervical cancer cells treated and untreated with ZER $\left(\mathrm{IC}_{50}\right)$ for 72 hours. Cells were cultured in RPMI 1640 (75 mL flask) media maintained at $37^{\circ} \mathrm{C}$ and $5 \% \mathrm{CO}_{2}$. Independent $t$-test showed a significant difference $\left({ }^{*} P<.05\right)$ between treated and untreated cells in the activity of caspase-3.

(independent $t$-test, $P<.05$ ) stimulated caspase-3, the hallmark enzyme of apoptosis. The level of this enzyme is higher in treated HeLa cells as compared to nontreated cells, this concludes that ZER induces cell death toward human cervical cancer cells, HeLa.

3.4. Quantification of Apoptosis Using Propidium Iodide and Acridine Orange Double Stainin. Apoptotic, necrotic, and viable HeLa cells were scored under fluorescence microscope. This is also included the control cells (untreated) whereby, 200 cells were randomly and differentially counted. The study revealed that ZER triggered morphological features that relates to apoptosis in a time-dependent manner (Figures 3(a), 3(b), 3(c), and 3(d)). Whereby, early apoptosis is obvious by intercalated $\mathrm{AO}$ within the fragmented DNA. In several of such cases, the fluorescent bright-green color could be seen in treated HeLa cells only. In contrast, untreated cells were observed with a green intact nuclear structure. At 48hour treatment with ZER, blebbing and nuclear margination were noticed (moderate apoptosis). In addition, late stages of apoptosis, such as apoptotic body separation and presence of reddish-orange color due to the binding of $\mathrm{AO}$ to denatured DNA, were observed after 72-hour treatment with
ZER. Differential scoring of treated HeLa cells (200 cells population) showed that there is a statistical significant $(P$ $<.05)$ difference in apoptosis positive cells, which indicates clearly that ZER has a time-dependent apoptogenic effect. On the other hand, there was no statistical significant $(P>$ $.05)$ difference in necrotic counts at different treatment times $(24,48$, and 72 hours) (Figure 4$)$.

3.5. Effects of ZER on Human Cervical Cancer Cells (HeLa) Using Scanning Electron Microscope (SEM). The surface ultrastructure of HeLa cells treated with ZER was examined. Interpretation of SEM electromicrographs showed distinct morphological changes corresponding to a typical cellular surface morphology of apoptosis, including cell membrane blebbing, microvilli disappearance or reduction (Blunt microvillus), and separated apoptotic bodies. The effects of ZER on HeLa cells were found to be timecorrelated phenomena (Figures 5(b), 5(c), and 5(d)) and this was noticed when considering the number of blebs (cytoplasmic extension) as an indicator of cell death via apoptosis. Untreated HeLa cells have shown a restoration of the typical morphological features of cervical cancer cells which include numerous microvilli on its surface with membrane connections (Figure 5(a)). However, occasional existence of rounded cells and blebbing on the cell surface are characteristics of HeLa cells in culture but this phenomenon is not rampant. Although a few cells from the control groups resembled those from treated groups, ZER caused morphological alterations in a larger proportion of cells.

3.6. Effects of ZER on Cervical Human Cancer Cells (HeLa) Using Transmission Electron Microscopy. ZER-treated HeLa cells showed death corresponded very well to the crosssectional classical signs of apoptosis: cell shrinkage, increased cellular granularity, the formation of apoptotic bodies, and dilated nuclear membranes (Figures 6(b), 6(d), and 6(e)). Mitochondrial cristae in ZER-treated cancer cells were ruptured and condensed (Figure 6(c)). The evidences which suggested that the apoptogenic effect of ZER on HeLa cells is time-dependent manner were obtained through observation of dynamic micrographs images using transmission electron microscopy. The initial induction of cell death indicates primary (early) stage of apoptosis that involved cell shrinkage and chromatin condensation. Nuclear membrane dilatation and cell membrane blebbing (Figure 6(d)) were the next stage in this sequence of apoptosis followed by nuclear collapse and continual blebbing stage (48 hours). HeLa cells treated with ZER after 72 hours were observed to show late stages of apoptosis phenomena, which included apoptotic 


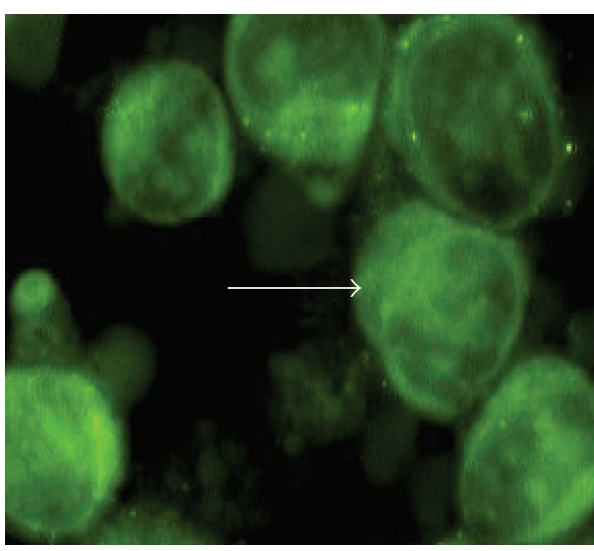

(a)

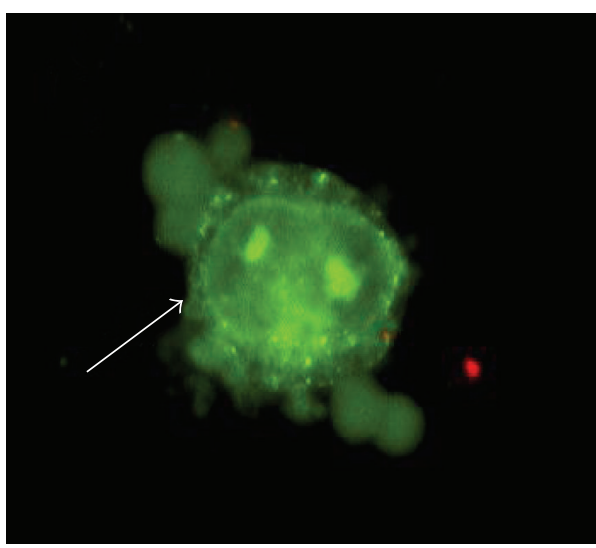

(c)

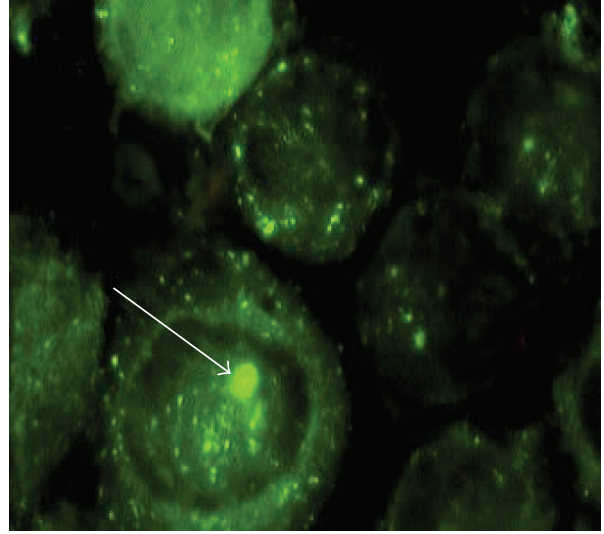

(b)

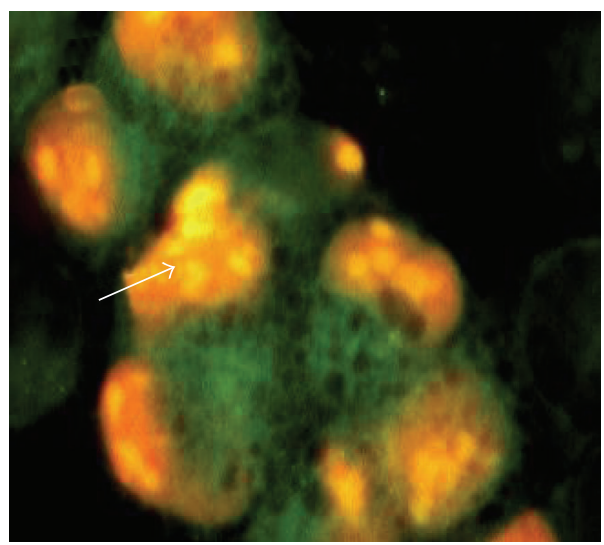

(d)

Figure 3: Fluorescent micrograph of acridine orange and propidium iodide double-stained human cervical cancer cells lines (HeLa). HeLa was treated at $\mathrm{IC}_{50}$ of ZER at time-dependent manner. Cells were cultured in RPMI 1640 media $\left(25 \mathrm{~mL}\right.$ flask) maintained at $37^{\circ} \mathrm{C}$ and $5 \%$ $\mathrm{CO}_{2}$. (a) Untreated cells showed normal structure without prominent apoptosis and necrosis. (b) Early apoptosis features were seen after 24 hours representing intercalated acridine orange (bright green) amongst the fragmented DNA. (c) Blebbing and nuclear margination were noticed in 48-hour treatment of ZER. (d) Late apoptosis was seen in 72 hours incubated cells, whereby positive staining with orange color represents the hallmark of late apoptosis (magnification 400X).

bodies formation (Figure 6(e)). Cisplatin-treated HeLa cells have shown similar morphological aspects of apoptosis, however, with fewer necrotic characteristics also observed.

\section{Discussion}

The results of current study reveal that zerumbone possesses promising antiproliferative properties against HeLa, MCF-7, and Coav-3 cancer cells. However, the lowest $\mathrm{IC}_{50}$ of ZER is obtained toward human cervical cancer cells (HeLa); therefore all investigations regarding the apoptogenic property of this natural product were carried on this cell line. On the other hand, ZER has shown a weaker cytotoxic effect on normal cells of $\mathrm{CHO}$. These cytoselective properties of ZER have been reported earlier $[4,17]$.

Apoptosis is biological phenomena that involved in process ranging from embryogenesis to ageing, from normal tissue homoeostasis to many human diseases. Apoptotic cells share a number of common features such as cell shrinkage, nuclear condensation, membrane blebbing, chromatin cleavage, and formation of pyknotic bodies of condensed chromatin $[20,21]$. These distinctive morphological features form the basis of some of the most widely used techniques for the identification and quantification of apoptosis, and thus morphologic description using light or electron microscopy remains one of the best ways to define apoptosis [21]. The programmed cell death (apoptosis) compared to necrosis is a desired somatic defense mechanism against cancer cells [22]. Moreover, apoptosis is reported earlier to be triggered by natural products $[23,24]$. Zerumbone is one of the promising natural products that possess potentiality to induce apoptosis on different cancer cell lines [25]. The current study was intended to provide an evidence of apoptosis on HeLa cells induced by ZER.

Cancer cell death phenomenon could be induced through different pathways [26]. A major part of this phenomenon could be mediated by caspase-3, the promoter of apoptosis [27]. This enzyme could be measured in vitro using colorimetric assay that recognize the amino acid sequence, DEVD, coupled with p-nitroanilide, which 


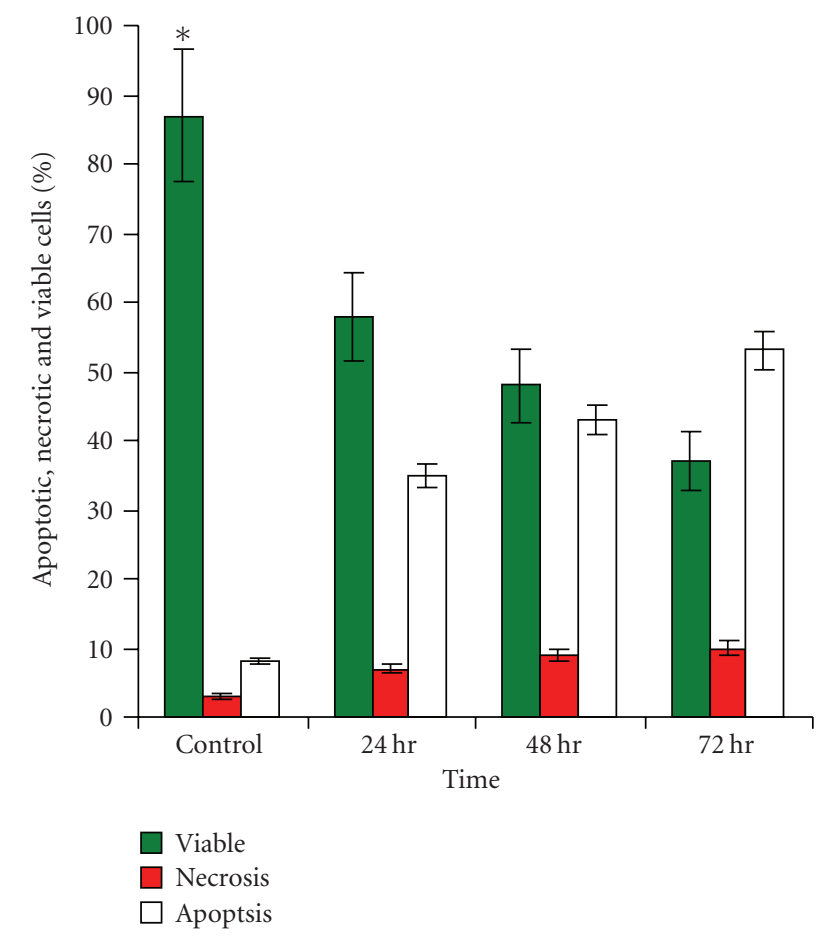

Figure 4: Percentages of viable, apoptotic, and necrotic cells after ZER treatment. HeLa cell death via apoptosis increased significantly $\left({ }^{*} P<.05\right)$ in time-dependent manner. However, no significant $(P>$ $.05)$ difference was observed in the cell count of necrosis. Cells were cultured in RPMI 1640 ( $25 \mathrm{~mL}$ flask) media maintained at $37^{\circ} \mathrm{C}$ and $5 \% \mathrm{CO}_{2}$.

is released upon substrate cleavage and can be detected at $405 \mathrm{~nm}$. This approach of measuring the caspases has been used previously in HeLa cells [28]. The present study revealed that ZER induced significantly (two-tailed $t$-test, $P<.05$ ) the elevation of caspase- 3 on HeLa as compared to untreated HeLa cells. These findings confirmed that ZER is capable of inducing apoptosis in HeLa cells by stimulating the enzymes that play a central role in the initiation of apoptosis. At this moment of writing, this study is the first to demonstrate that caspase- 3 activation is required for ZER-induced apoptosis in human cervical cancer cells (HeLa).

Nucleic acid specific fluorochromes emit fluorescent color when bound to DNA and this phenomenon can be viewed under fluorescence microscopy $[18,19]$. The fluorescent color of that stain is obtained by specific properties of different flourostain such as the ability to cross plasma membrane of viable cells and dead cells [18]. Using properties of AO/PI, HeLa cells were treated with ZER to study the antiproliferative and apoptogenic effects of ZER. The antiproliferative properties of ZER could then be evaluated by counting the numbers of viable cancer cells, while the apoptogenic effects were determined through observing typical morphological changes of apoptosis. This technique was previously applied to human colonic adenocarcinoma cells treated with ZER [11] and also toward HeLa treated with different compounds [29]. The cell viability results showed an obvious decrease of living cells in ZERtreated group. HeLa cells with ZER stimulation had typical morphological changes that implicate apoptosis such as DNA fragmentation, membrane blebbing, and apoptotic body formation, which could be evidenced by the visual brightgreen and orange color of $\mathrm{AO}$ color of stained cells under fluorescence microscopy. Apoptotic cells exhibit bright-green nucleus showing condensation of chromatin as dense-green areas. Quantification of apoptosis with differential scoring of treated and control HeLa cells revealed a significant $(P$ $<.05)$ difference in the number of apoptotic cells in a time-dependent manner but with insignificant difference between numbers of necrosis positive cells in control and treated cells, concluding that ZER did not induce necrotic effects. Confocal microscopy examination confirmed the onset of apoptosis features. These morphological criteria that implicate apoptotic cell death were further confirmed by scanning electron microscopy and transmission electron microscopy.

Apoptosis possesses distinctive morphological features which form the basis of some of the most widely used techniques for the identification and quantification of apoptosis. Thus, morphologic description of apoptosis using electron microscopy still remains one of the best ways to define apoptosis and to contrast it with necrosis [21]. Scanning electron microscopy (SEM) has been applied previously to study surface ultrastructural morphology of HeLa cells $[25,30]$. In the current investigation, SEM was employed to obtain detailed information about the cell surface of HeLa upon treatment with ZER at $\mathrm{IC}_{50}$ in a time-dependent manner (0, 24, 48, and 72 hours). SEM electromicrographs showed distinct morphological changes that correspond to a typical cellular surface morphology implicating apoptosis, including cell membrane blebbing, microvilli disappearance or reduction (blunt microvillus), and separated apoptotic bodies after treatment. These findings were similar that confirms to previous reported cytological features of HeLa cells undergoing apoptosis [30]. Untreated HeLa cells have shown a restoration of the typical morphological features of cervical cancer cells, which included numerous microvilli (hairing rods) on the cell surface with membrane connections. These results strongly provide evidence that ZER has promising anticancer activity toward human cervical cancer based on the observation of distinctive morphological features to surface HeLa cells upon treatment with ZER.

In this study, the ultrastructural changes in HeLa cells after treatment with ZER were studied using transmission electron microscopy (TEM). TEM has been utilized commonly as the tool to study the morphological ultrastructure of cells [31]. The application of TEM technology is also used in the detection of associated cellular microlesions of apoptosis and cell cycle arrest $[32,33]$. In addition, TEM allows the opportunity to view cytoplasmic changes [34] which cannot be viewed using SEM. TEM is a powerful technique for differentiating between apoptosis and necrosis [35], allows the analysis of sectioned specimens, and provides a qualitative bidimensional image of the inner cell, often after fixation, embedding, and staining [36, 37]. The TEM electromicrograph exhibited defined chromatin margination, followed 


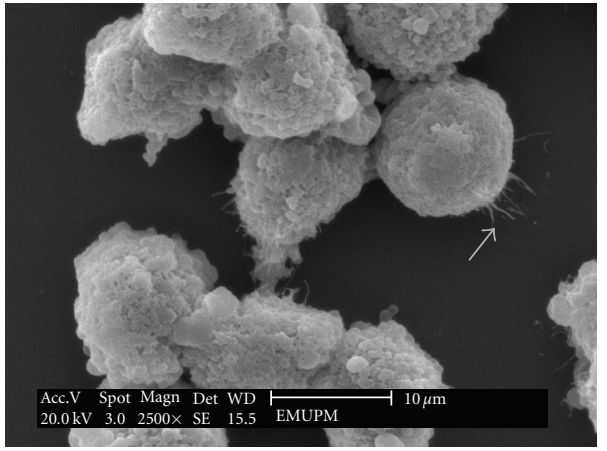

(a)

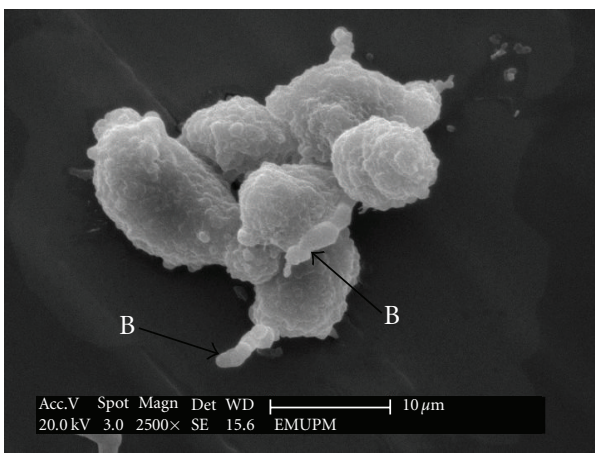

(c)

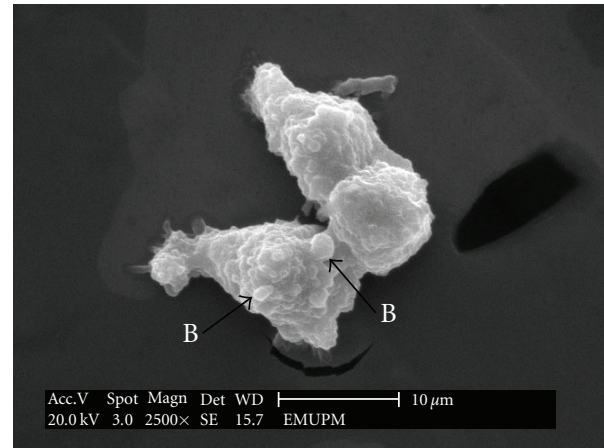

(b)

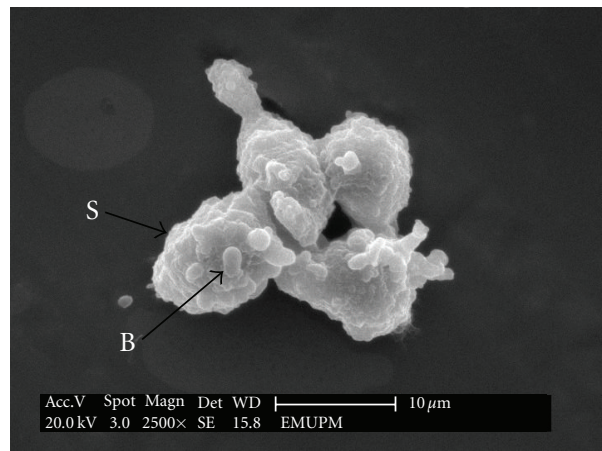

(d)

FIgURE 5: SEM micrographs of surface ultrastructural characteristics of HeLa cells treated with ZER in time-dependent manner (0, 24, 48, and 72 hours) and cultured in RPMI 1640 media maintained at $37^{\circ} \mathrm{C}$ and $5 \% \mathrm{CO}_{2}$. (a) The characteristic of untreated HeLa cells surface showing the restoration of a typical morphological feature of a cancer cell such as numerous microvilli (as shown in grey arrow) with several membrane connections. (b), (c), and (d) ZER-treated HeLa cells (24, 48, and 72 hours, $\left.\mathrm{IC}_{50}: 20.41 \mu \mathrm{M}\right)$ showed distinct morphological changes corresponding to typical apoptosis, including cell membrane blebbing (b), microvilli disappearance or reduction (blunt microvillus (s)), and separated apoptotic bodies (X2500).

by the cell compaction toward the nuclear periphery. In the residual diffuse chromatin, remnants of deeply modified nucleoli can still be revealed in treated HeLa cells. The nucleus appears strongly rearranged, if compared to normal, which the later shows uncondensed heterochromatin, clearly distinguishable from the diffuse interchromatin of treated cells. Plasma membrane and organelles are preserved for long, except for cytosol condensation and blebbing phenomena, which characterize apoptotic models. Subsequently, the nucleus generates numerous compact electron dense micronuclei, frequently released in the extracellular space. Cell splitting in a number of apoptotic bodies represents generally the final stage of apoptosis.

Apoptosis as a desired biodefense cell death can be induced in cancer tissues [38]. This induction is made possible using natural products from a variety of plantsderived compounds [39]. One of these natural compounds of plant derived is terpenoids [40], which included mono-, sesqui-, di-, and triterpenoids. These biocompounds are synthesized by tandem reactions of the phosphorylated isoprene unit [41]. Some of these dietary compounds possess chemopreventive properties that have been proven in vivo and in vitro. For example, d-limonene from the peel oil of orange or lemon has a chemopreventive activity against mammary, skin, liver, lung, and fore stomach carcinogenesis [42]. Clinical trials results also demonstrated that some terpenoids have the potentiality for treating cancers without major toxicity [43]. Thus, further understanding of their biological and physiological mechanisms may lead to the identification of more effective compounds in this category for the prevention and treatment of targeted cancer types. ZER (mono-sesquiterpene) has been reported previously to induce apoptosis in several cancer cell lines such as liver cancer [4] and leukemia cell lines [25]. ZER has also been reported having the capability to induce apoptotic and morphological changes in different types of leukemic cells [44]. On the other hand, ZER has shown less cytotoxic effect on normal Chang liver cells, normal human dermal (2F0-C25), and colon (CCD-18 Co) fibroblasts [4, 17]. The current results of this study are in agreement with previous studies in terms of the potential anticancer of this compound and the typical features of apoptosis of HeLa $[4,14,20]$. This current study of using TEM technique has been concluded for the first time, the compound ZER, having promising anticancer activity toward HeLa cancer cells. In addition, TEM has never been used and reported before to include the study that relates to ultrastructural changes occurring to the HeLa cancer cells upon treatment by ZER. 


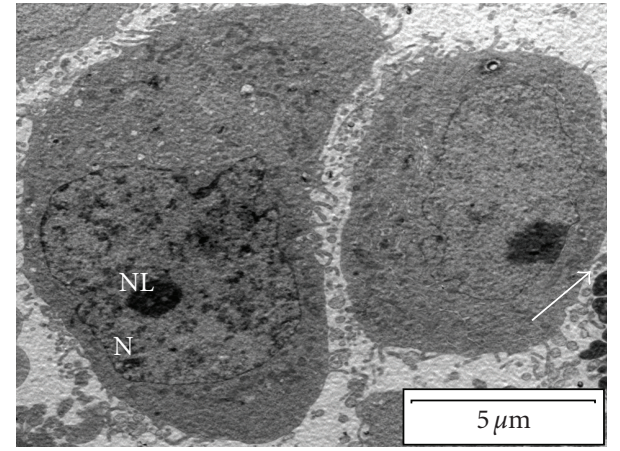

(a)

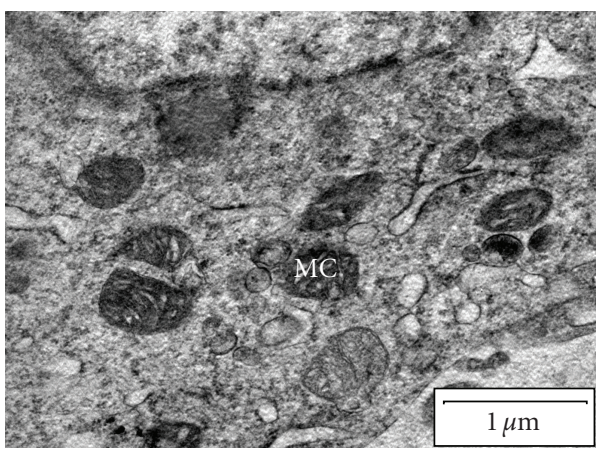

(c)

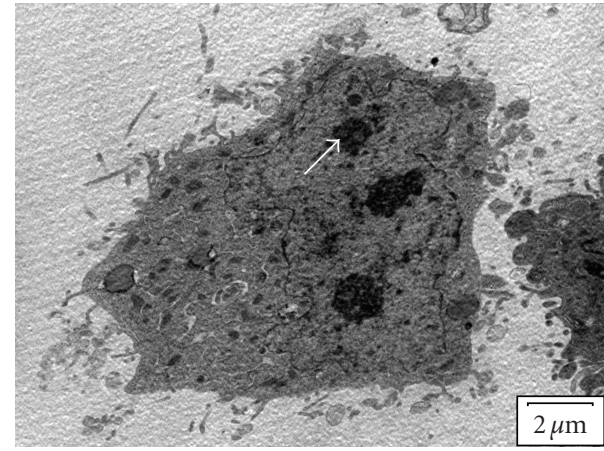

(b)

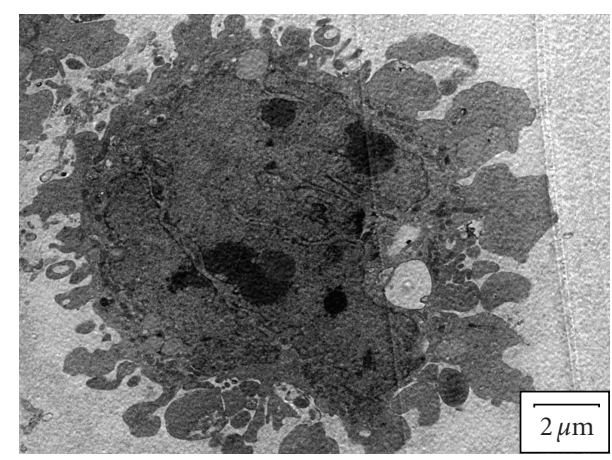

(d)

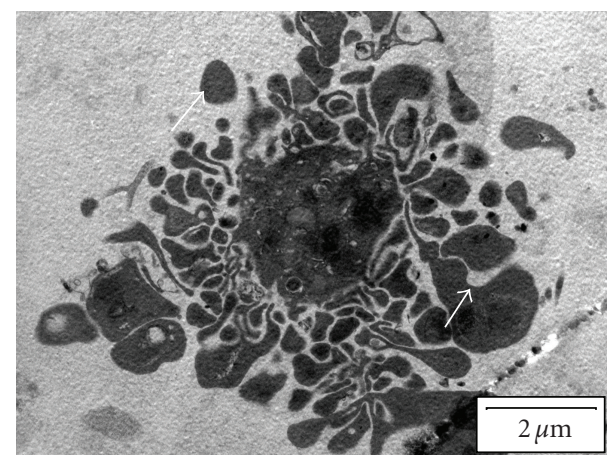

(e)

FIgURE 6: (a) Electromicrograph of untreated human cervical cancer cells (HeLa) demonstrates the normal structure of HeLa cancer cell. Nucleus (N), nucleolus (NL), and the cytoplasm appeared without abnormal changes (X4600). (b) ZER-treated (24 hours) human cervical cancer cells (HeLa) demonstrate morphological features of early apoptosis: cell shrinkage, chromatin condensation (arrow), and integrity of plasma membrane (X6000). (c) ZER-treated human cervical cancer cells (HeLa) demonstrate the condensed cristae of mitochondria (MC) as a typical morphological feature in apoptosis (arrow) (X27500). (d) ZER-treated (48 hours) human cervical cancer cell line (HeLa) demonstrates morphological features of intermediate apoptosis: cell shrinkage, chromatin condensation (white arrow), and membrane blebbing (small white arrow) (X6000). (e) ZER-treated (72 hours) cervical cancer cells (HeLa) demonstrate morphological feature of late apoptosis: nuclear collapse, continuing blebbing, and apoptotic body formation (arrow) (X10 000). Cells were cultured in RPMI 1640 (25 mL flask) media maintained at $37^{\circ} \mathrm{C}$ and $5 \% \mathrm{CO}_{2}$.

It has been reported that zerumbone inhibits the proliferation of cancer cells, while having less effect on normalcell proliferation [17]. This report pointed to the $\alpha, \beta$ unsaturated carbonyl group in ZER as the likely source of the activity, and this group may play an important role. The $\alpha, \beta$-unsaturated carbonyl group effectively removes the intracellular Glutathione (GSH) by forming the Michael adduct with it, thereby raising intracellular redox potential
$(E)$, which in turn stops the proliferation of the cancer cells $[45,46]$. However, average intracellular redox potential of normal fibroblasts is about $-220 \mathrm{mV}$, and that in proliferating fibrosarcoma cells is about $-210 \mathrm{mV}$, this difference could explained the weaker effect of ZER on the proliferation of normal cells. There is, thus, a margin of $\sim 10 \mathrm{mV}$ in the adjustability of $E$ between these normal cells and the cancer cells $[45,46]$. 
In conclusion, ZER has stronger cytotoxic effects toward cancer cells compared to normal cells. This compound can stimulate apoptosis of HeLa cells. ZER would have a bright future in the treatment of tumors and further work may lead to relative antitumor agents to be used in clinical settings.

\section{Acknowledgments}

This research was funded in part by the National Cancer Council (MAKNA), Malaysia. The authors also acknowledge additional support from Universiti Putra Malaysia (UPM), Serdang, Malaysia (Grant no. RUGS 91143).

\section{References}

[1] Y. J. Song, D. Y. Lee, S.-N. Kim, et al., "Apoptotic potential of sesquiterpene lactone ergolide through the inhibition of NF$\kappa \mathrm{B}$ signaling pathway," Journal of Pharmacy and Pharmacology, vol. 57, no. 12, pp. 1591-1597, 2005.

[2] T. K. Tabopda, J. Liu, B. T. Ngadjui, and B. Luu, "Cytotoxic triterpene and sesquiterpene lactones from Elephantopus mollis and induction of apoptosis in neuroblastoma cells," Planta Medica, vol. 73, no. 4, pp. 376-380, 2007.

[3] N. Somchit and M. H. Nur-Shakirah, "Anti inflammatory property of ethanol and water extracts of Zingiber zerumbet," Indian Journal of Pharmacology, vol. 35, no. 3, pp. 181-182, 2003.

[4] S. A. S. Sakinah, S. Tri Handayani, and L. P. Azimahtol Hawariah, "Zerumbone induced apoptosis in liver cancer cells via modulation of Bax/Bcl-2 ratio," Cancer Cell International, vol. 7, article 4, pp. 1-11, 2007.

[5] T. Y. Chien, L. G. Chen, C. J. Lee, F. Y. Lee, and C. C. Wang, "Anti-inflammatory constituents of Zingiber zerumbet," Food Chemistry, vol. 110, no. 3, pp. 584-589, 2008.

[6] C. Kirana, G. H. McIntosh, I. R. Record, and G. P. Jones, "Antitumor activity of extract of Zingiber aromaticum and its bioactive sesquiterpenoid zerumbone," Nutrition and Cancer, vol. 45, no. 2, pp. 218-225, 2003.

[7] H. W. D. Matthes, B. Luu, and G. Ourisson, "Cytotoxic components of Zingiber zerumbet, Curcuma zedoaria and C. domestica," Phytochemistry, vol. 19, no. 12, pp. 2643-2650, 1980.

[8] A. Murakami, T. Tanaka, J.-Y. Lee, et al., "Zerumbone, a sesquiterpene in subtropical ginger, suppresses skin tumor initiation and promotion stages in ICR mice," International Journal of Cancer, vol. 110, no. 4, pp. 481-490, 2004.

[9] T. Tanaka, M. Shimizu, H. Kohno, et al., "Chemoprevention of azoxymethane-induced rat aberrant crypt foci by dietary zerumbone isolated from Zingiber zerumbet," Life Sciences, vol. 69, no. 16, pp. 1935-1945, 2001.

[10] D. Nirmala, B. Ahmad, and H. Nazrul, Anti-tumer effects of Zerumbone on DES induced Cervical Cancer, M.S. thesis, Universiti Putra Malaysia, Kuala Lumpur, Malaysia, 2007.

[11] A. Murakami, R. Hayashi, T. Takana, K. H. Kwon, H. Ohigashi, and R. Safitri, "Suppression of dextran sodium sulfateinduced colitis in mice by zerumbone, a subtropical ginger sesquiterpene, and nimesulide: separately and in combination," Biochemical Pharmacology, vol. 66, no. 7, pp. 1253-1261, 2003.

[12] A. Bustamam, S. Ibrahim, A. S. Al-Zubairi, M. MET, and M. M. Syam, "Zerumbone: a natural compound with anticholinesterase activity," American Journal of Pharmacology and Toxicology, vol. 3, no. 3, pp. 209-211, 2008.
[13] J. Monsonégo, "Cervical cancer prevention: the impact of HPV vaccination," Gynecologie Obstetrique Fertilite, vol. 34, no. 3, pp. 189-201, 2006.

[14] Y. Liu, H. Xing, X. Han, et al., "Apoptosis of HeLa cells induced by cisplatin and its mechanism," Journal of Huazhong University of Science and Technology-Medical Science, vol. 28, no. 2, pp. 197-199, 2008.

[15] X. Wang, T. H. Beckham, J. C. Morris, F. Chen, and J. D. Gangemi, "Bioactivities of gossypol, 6-methoxygossypol, and 6, 6' -dimethoxygossypol," Journal of Agricultural and Food Chemistry, vol. 56, no. 12, pp. 4393-4398, 2008.

[16] A. S. Al-Zubairi, A. B. Abdul, I. A. Siddig, and M. N. Somchit, "Genotoxicity of Zerumbone in human peripheral blood lymphocytes evaluated by cytogenetic test," in Proceedings of 6th International Traditional/Complementary Medicine Conference (INTRACOM '07), PWTC, Kuala Lumpur, Malaysia, July 2007.

[17] A. Murakami, D. Takahashi, T. Kinoshita, et al., "Zerumbone, a Southeast Asian ginger sesquiterpene, markedly suppresses free radical generation, proinflammatory protein production, and cancer cell proliferation accompanied by apoptosis: the $\alpha, \beta$-unsaturated carbonyl group is a prerequisite," Carcinogenesis, vol. 23, no. 5, pp. 795-802, 2002.

[18] B. B. Mishell, S. M. Shiiqi, and C. Henry, "Selected methods," in Cellular Immunology, B. B. Mishell and S. M. Shiiqi, Eds., pp. 21-22, Freeman, San Francisco, Calif, USA, 1980.

[19] T. Guan, F. Qin, J. Du, L. Geng, Y. Zhang, and M. Li, "AICAR inhibits proliferation and induced S-phase arrest, and promotes apoptosis in CaSki cells," Acta Pharmacologica Sinica, vol. 28, no. 12, pp. 1984-1990, 2007.

[20] J.-C. Lin, Y.-S. Ho, J.-J. Lee, C.-L. Liu, T.-L. Yang, and C.-H. $\mathrm{Wu}$, "Induction of apoptosis and cell-cycle arrest in human colon cancer cells by meclizine," Food and Chemical Toxicology, vol. 45, no. 6, pp. 935-944, 2007.

[21] F. Doonan and T. G. Cotter, "Morphological assessment of apoptosis," Methods, vol. 44, no. 3, pp. 200-204, 2008.

[22] L. Mandoky, B. Szende, L. Géczi, I. Bodrogi, M. Kásler, and M. Bak, "Apoptosis regulation and spontaneous apoptosis index of testicular germ cell tumors are associated with differentiation and resistance to systemic treatment," Anticancer Research, vol. 28, no. 3A, pp. 1641-1649, 2008.

[23] J. Zhou, G.-D. Lu, C.-S. Ong, C.-N. Ong, and H.-M. Shen, "Andrographolide sensitizes cancer cells to TRAIL-induced apoptosis via p53-mediated death receptor 4 up-regulation," Molecular Cancer Therapeutics, vol. 7, no. 7, pp. 2170-2180, 2008.

[24] S. M. Lee, J. I. Kwon, Y. H. Choi, H. S. Eom, and G. Y. Chi, "Induction of G2/M arrest and apoptosis by water extract of Strychni Semen in human gastric carcinoma AGS cells," Phytotherapy Research, vol. 22, no. 6, pp. 752-758, 2008.

[25] M. Xian, K. Ito, T. Nakazato, et al., "Zerumbone, a bioactive sesquiterpene, induces G2/M cell cycle arrest and apoptosis in leukemia cells via a Fas- and mitochondria-mediated pathway," Cancer Science, vol. 98, no. 1, pp. 118-126, 2007.

[26] R. C. Humphreys and W. Halpern, "Trail receptors: targets for cancer therapy," Advances in Experimental Medicine and Biology, vol. 615, pp. 127-158, 2008.

[27] C.-F. Lin, Y.-H. Lo, M.-C. Hsieh, Y.-H. Chen, J.-J. Wang, and M.-J. Wu, "Cytotoxicities, cell cycle and caspase evaluations of 1,6-diaryl-3(Z)- hexen-1,5-diynes, 2-(6-aryl-3(Z)-hexen-1,5diynyl)anilines and their derivatives," Bioorganic \& Medicinal Chemistry, vol. 13, no. 10, pp. 3565-3575, 2005.

[28] G. Ren, Y.-p. Zhao, L. Yang, and C.-X. Fu, "Anti-proliferative effect of clitocine from the mushroom Leucopaxillus giganteus on human cervical cancer HeLa cells by inducing apoptosis," Cancer Letters, vol. 262, no. 2, pp. 190-200, 2008. 
[29] D. Ren, G. Peng, H. Huang, H. Wang, and S. Zhang, "Effect of rhodoxanthin from Potamogeton crispus L. on cell apoptosis in Hela cells," Toxicology in Vitro, vol. 20, no. 8, pp. 1411-1418, 2006.

[30] S. K. Majumdar, J. A. Valdellon, and K. A. Brown, "In vitro investigations on the toxicity and cell death induced by tamoxifen on two non-breast cancer cell types," Journal of Biomedicine and Biotechnology, vol. 1, no. 3, pp. 99-107, 2001.

[31] M. Guha, P. Maity, V. Choubey, K. Mitra, R. J. Reiter, and U. Bandyopadhyay, "Melatonin inhibits free radicalmediated mitochondrial-dependent hepatocyte apoptosis and liver damage induced during malarial infection," Journal of Pineal Research, vol. 43, no. 4, pp. 372-381, 2007.

[32] H.-B. Zhou and J.-R. Zhu, "Paclitaxel induces apoptosis in human gastric carcinoma cells," World Journal of Gastroenterology, vol. 9, no. 3, pp. 442-445, 2003.

[33] K. R. Mills, M. Reginato, J. Debnath, B. Queenan, and J. S. Brugge, "Tumor necrosis factor-related apoptosis-inducing ligand (TRAIL) is required for induction of autophagy during lumen formation in vitro," Proceedings of the National Academy of Sciences of the United States of America, vol. 101, no. 10, pp. 3438-3443, 2004.

[34] E. Pretorius, M. S. Bornman, J. Marx, E. Smit, and C. F. van der Merwe, "Ultrastructural effects of low dosage endocrine disrupter chemicals on neural cells of the chicken embryo model," Hormone and Metabolic Research, vol. 38, no. 10, pp. 639-649, 2006.

[35] D.-S. Zhang, L. Liu, L.-Q. Jin, M.-L. Wan, and Q.-H. $\mathrm{Li}$, "Effect of phosphorus-32 glass microspheres on human hepatocellular carcinoma in nude mice," World Journal of Gastroenterology, vol. 10, no. 11, pp. 1551-1554, 2004.

[36] L. Stuppia, P. Gobbi, L. Zamai, G. Palka, M. Vitale, and E. Falcieri, "Morphometric and functional study of apoptotic cell chromatin," Cell Death and Differentiation, vol. 3, no. 4, pp. 397-405, 1996.

[37] J. Pei, E. Strehler, U. Noss, et al., "Quantitative evaluation of spermatozoa ultrastructure after acupuncture treatment for idiopathic male infertility," Fertility and Sterility, vol. 84, no. 1, pp. 141-147, 2005.

[38] K. Kang, H. J. Lee, C. Y. Kim, et al., "The chemopreventive effects of Saussurea salicifolia through induction of apoptosis and phase II detoxification enzyme," Biological and Pharmaceutical Bulletin, vol. 30, no. 12, pp. 2352-2359, 2007.

[39] C. Matito, F. Mastorakou, J. J. Centelles, J. L. Torres, and M. Cascante, "Antiproliferative effect of antioxidant polyphenols from grape in murine Hepa-1c1c7," European Journal of Nutrition, vol. 42, no. 1, pp. 43-49, 2003.

[40] Z. Tian, Y.-M. Liu, S.-B. Chen, et al., "Cytotoxicity of two triterpenoids from Nigella glandulifera," Molecules, vol. 11, no. 9, pp. 693-699, 2006.

[41] B. F. Rasulev, A. I. Saidkhodzhaev, S. S. Nazrullaev, K. S. Akhmedkhodzhaeva, Z. A. Khushbaktova, and J. Leszczynski, "Molecular modelling and QSAR analysis of the estrogenic activity of terpenoids isolated from Ferula plants," SAR and QSAR in Environmental Research, vol. 18, no. 7-8, pp. 663-673, 2007.

[42] D. Gao, Z. Xiao, and A. E. Lü, "Proliferation inhibition and apoptosis induction of K562 cells by D-limonene," Zhongguo Shi Yan Xue Ye Xue Za Zhi, vol. 14, no. 6, pp. 1120-1122, 2006.

[43] X. Liu, J.-H. Wang, and J.-P. Yuan, "Pharmacological and antitumor activities of ganoderma spores processed by top-down approaches," Journal of Nanoscience and Nanotechnology, vol. 5, no. 12, pp. 2001-2013, 2005.
[44] A. Hamid, A. M. Ali, N. F. Rajab, N. B. Alitheen, H. Sirat, and A. A. Bakar, "Zerumbone causes morphological changes on different types of leukemic cell lines," in Proceeding of the 24th Annual Conference of the Microscopy Society of Thailand, Kasetsart University, Bangkok, Thailand, February 2007.

[45] A. Hoffman, L. M. Spetner, and M. Burke, "Cessation of cell proliferation by adjustment of cell redox potential," Journal of Theoretical Biology, vol. 211, no. 4, pp. 403-407, 2001.

[46] A. Hoffman, L. M. Spetner, and M. Burke, "Redox-regulated mechanism may account for zerumbone's ability to suppress cancer-cell proliferation," Carcinogenesis, vol. 23, no. 11, pp. 1961-1963, 2002. 


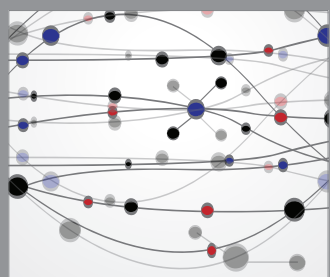

The Scientific World Journal
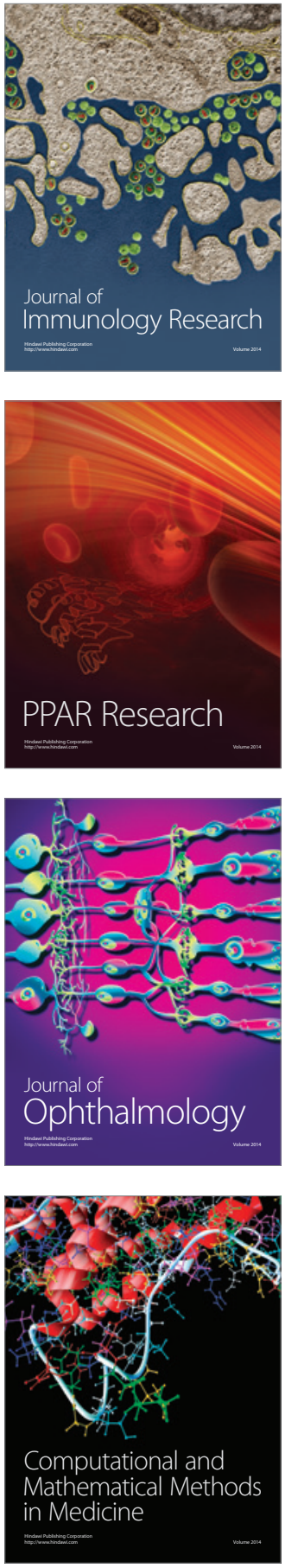

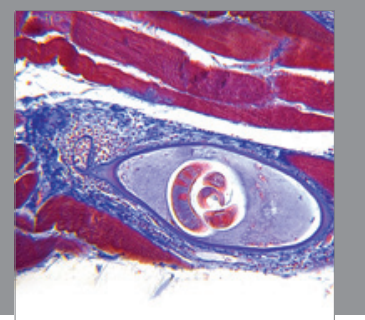

Gastroenterology

Research and Practice
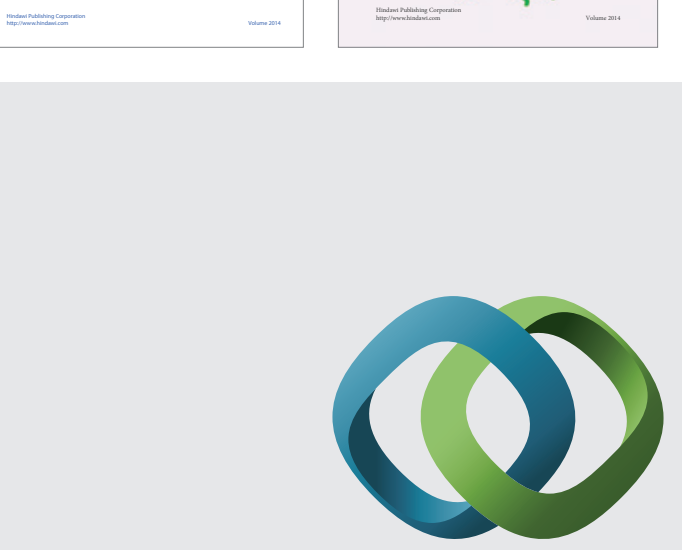

\section{Hindawi}

Submit your manuscripts at

http://www.hindawi.com
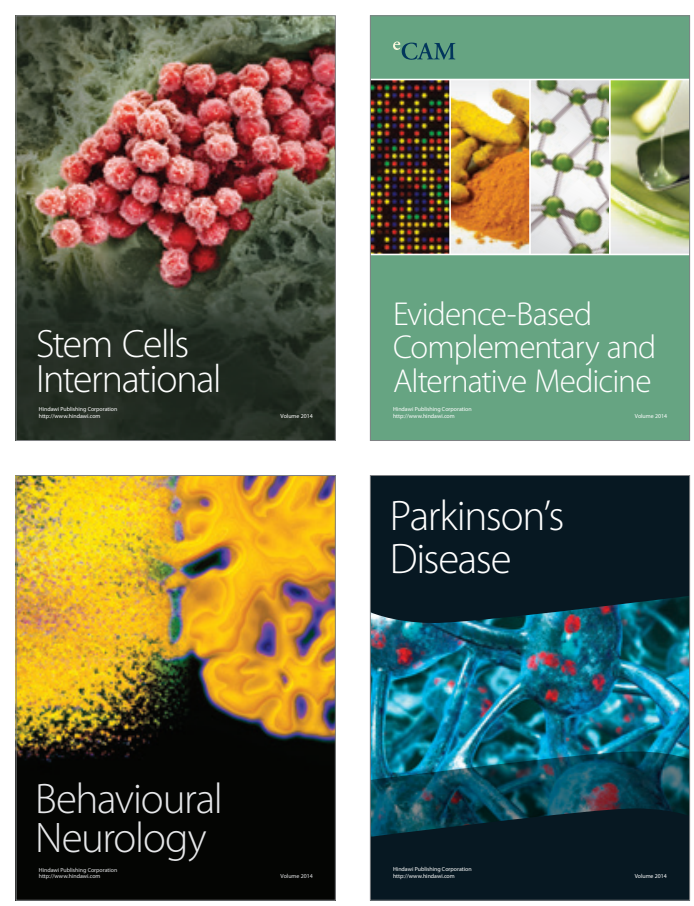

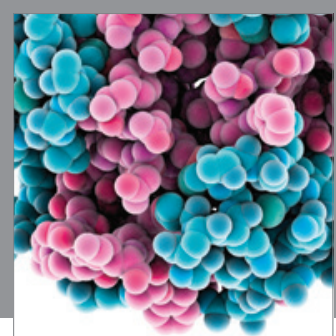

Journal of
Diabetes Research

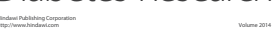

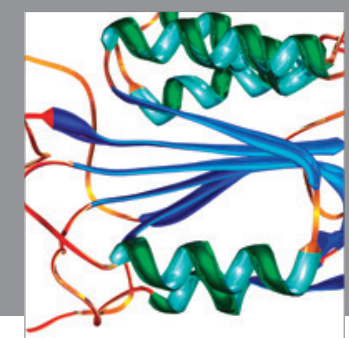

Disease Markers
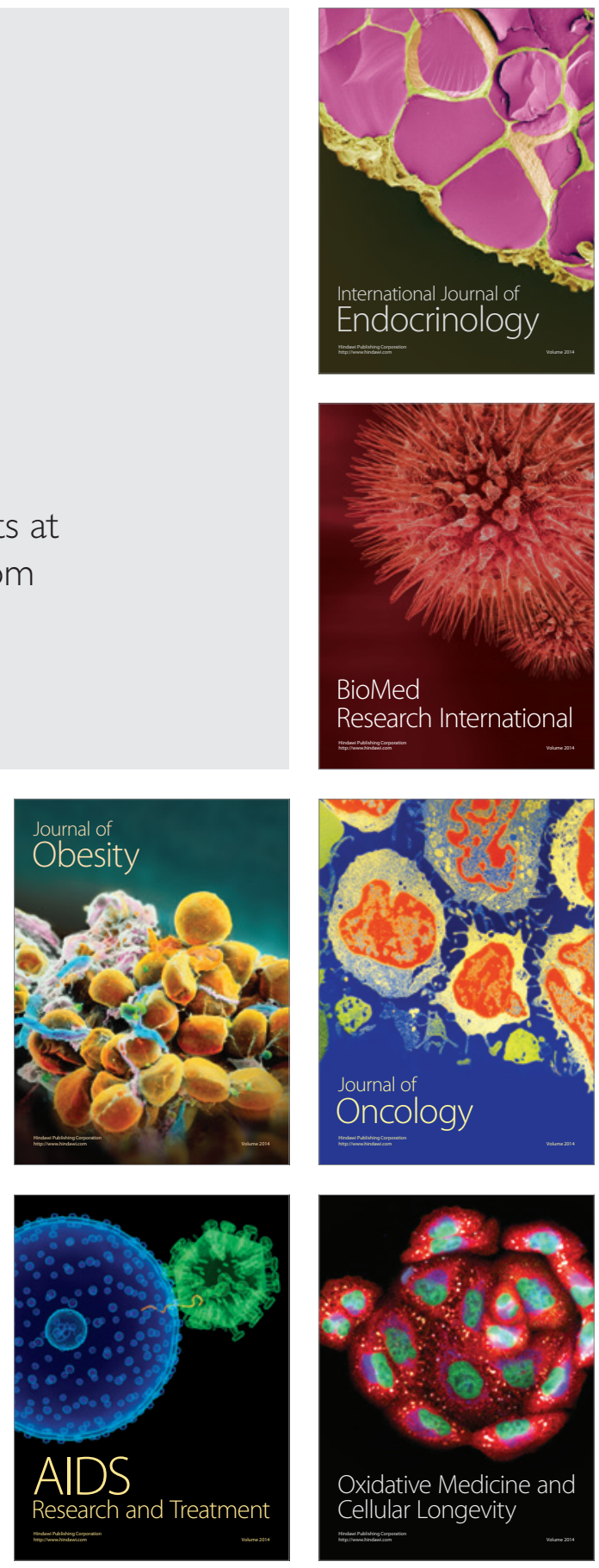